\title{
GEOMAGNETIC VARIATIONS AND DIURNAL RANGE \\ OF ATMOSPHERIC OZONE
}

\author{
S. L. MaLurkar
}

Dolson. Harrison and Lawrence (1927, found "the apparent connection hetween the annount of ozone and the ' $H$ ' range is much more marked on days of high magnetic character, the days of low character showing little differentiation hetween the amounts of ozone corresponding to high and low ' $I$ ' range". But sulsequently (1929) they remarked "It was thought that a closer relation might he found ly using the mean ozone values for $\mathrm{N}$. W. Europe and the mean machetic character for several stations in the same region... instead of the relation heing closer, as was expected, it is entirely alsent. This is a curious result which we cannot explain at present".

In connection with other studies, it was thought that the question may arain be looked into. Apart from the mean value of ozone, it is possible to get the diurnal range also these dayz. The variations in the mean value and those in the range of ozone can he independant. Further, in these vears it is the usual rule to get at more detailed pictures of magnetic variations in the $C$ and $K$ indices which represent the mannetic character for the whole day and the magnetic fluctuations alsout its normal curve at three hourly intervals of the earth"s horizontal field.

Tonshery and Olsen 1941 have pullished the daily amounts of ozone and its daily range at Tromso. For the years 1941 and 1942, the values are arailable over a large number of days to compare with the mean world geomagnetic $K$ figures (IATME 1948). The diurnal range of ozone for 1951 at Tromes is also available (Tromso, 1953 : In the same publication the $K$ magnetic figure: for Troms and Bear Id. are given. The mean value of $K$ indices for these two ohservatories has been used for 1951.

The actual daily figures of ozone diurnal variation in units of 0.001 cm and the daily sum of the 3 hour character figures are reproduced in the graphs. The continuous lines connect the geo-magnetic figures and the dotted lines connect the values of diurnal amounts of 
210

S. L. MALURKAR
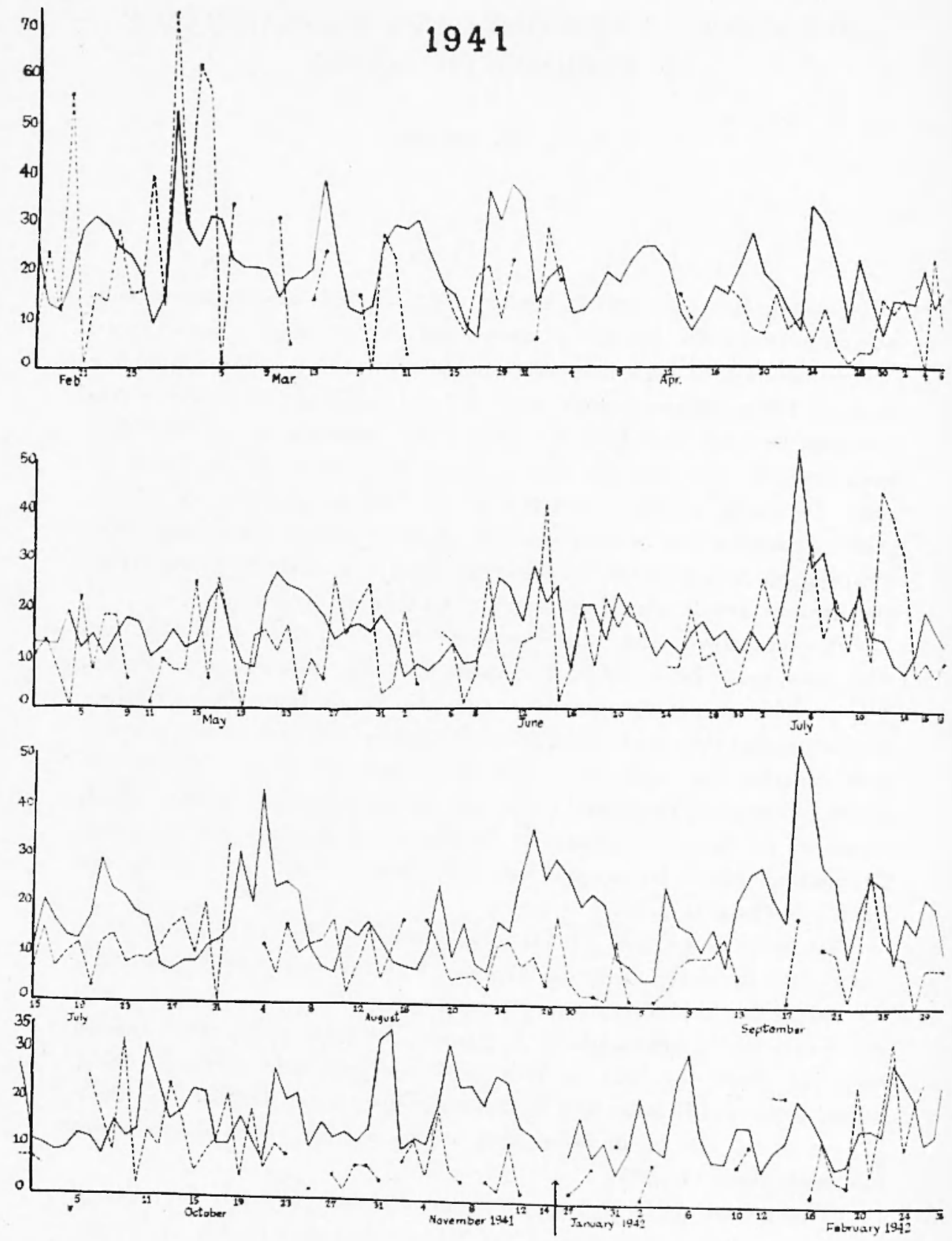

Fig. 1 


\section{2}
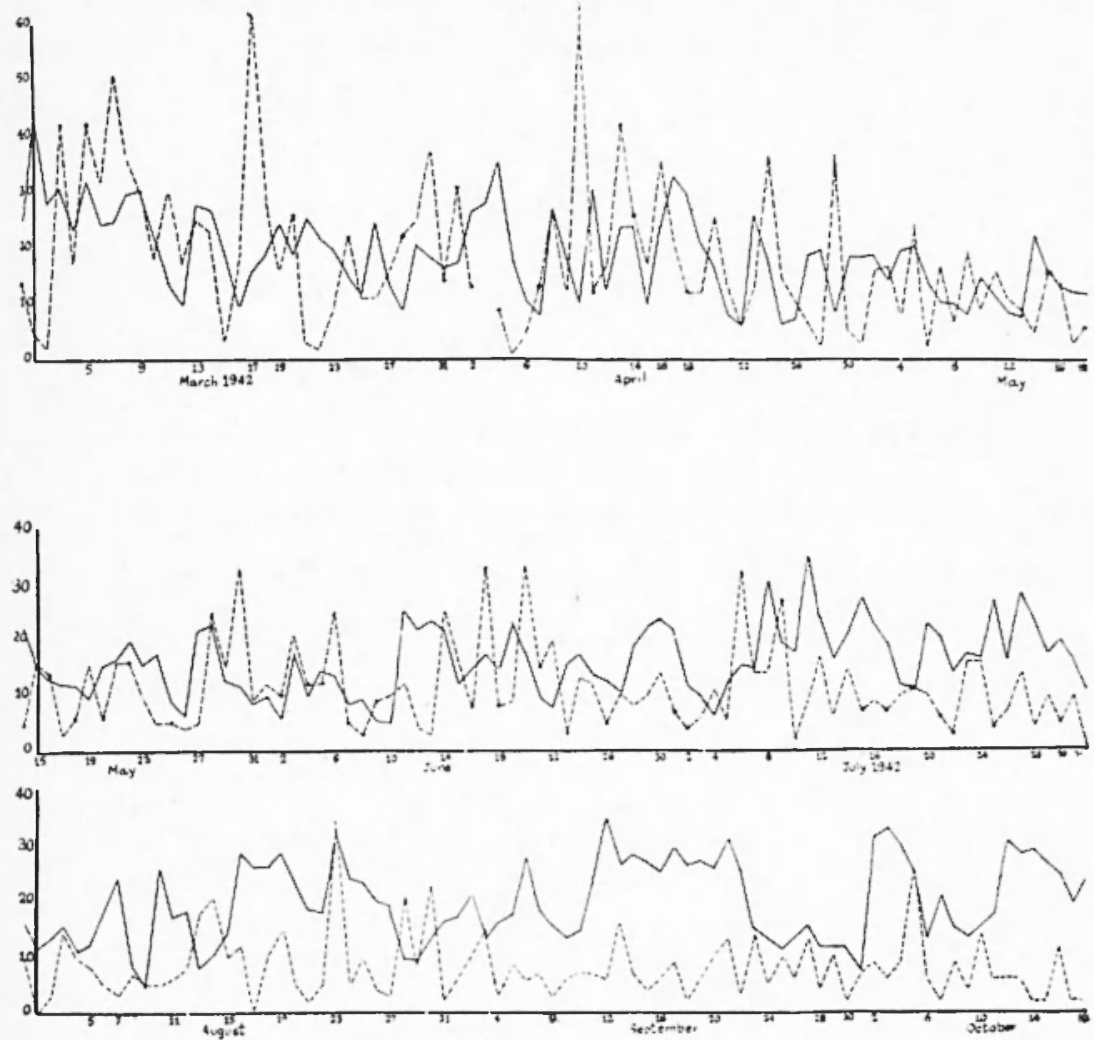

Fig. 2

ozone. The graphs show a good co-ordination. If the value of diurnal range of atmospheric ozone increases; at about the same epoch (within 24 hours on either side), the magnetic character sum is also found to have increased. While the magnetic character, once having increased, takes some days to drop back to its nornal or original value. the diurnal range of ozone drops back rapidly; i. e. while the increase of the diurnal range of ozone and the rise of the magnetic character seem to be contemporaneous, the drop in the diurnal range of ozone is not necessarily contemporaneous with the fall of the magnetic character.

Among the remarkable coincidences are June. 13-14th. 1951 a day of solar flare crochet at Alibag followed by a magnetic storm on 14th and Mar. lst. 1941 when a magnetic storm occurred may be noticed. 


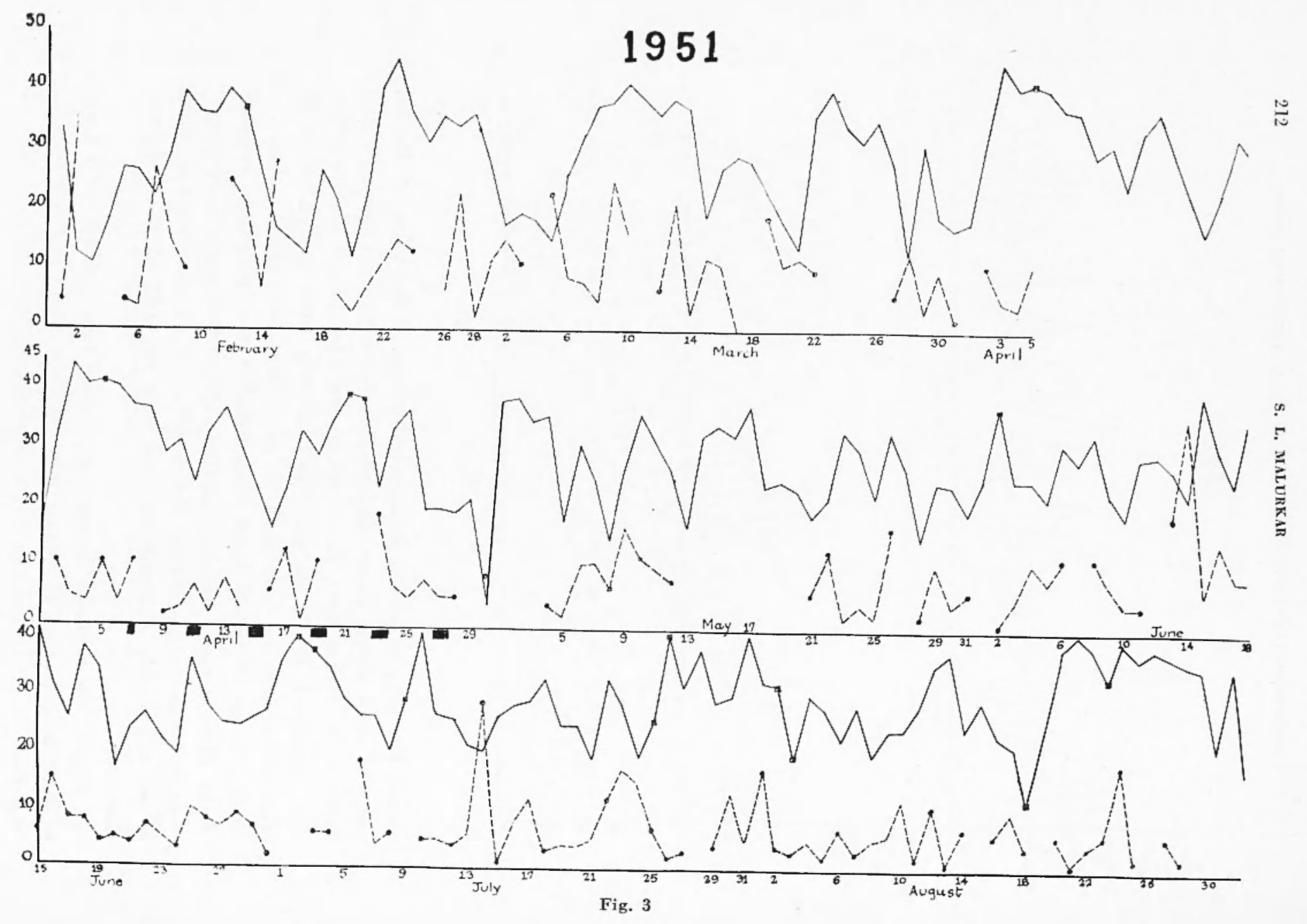


I thank Prof. D. D. Kosambi for confirning the graphical deduction. The Agricultural Meteorology Section (Poona) and Mr. M. Panluranđa Rao for helping me in ohtaining the diagrams.

\section{REFERFNC:ES}

Dorsox G. M. B., Harmsox D. N. and Lawrevce: J. Proc. Roy. Soc. A 114, $521,1927$.

Dobson G. M. B., Harnisox D. N. and Lawrexce: J. Proc. Roy. Soc. A 122, 4.56. 1929 .

IATME: Bull. Nir. 12. International Union of Geodesy and Geophysics Geomagnetic Indires. $C$ and $\mathrm{K}$ 19.11.19.46. Washington, 1918.

Toxsbtikg. Einar and Oleen. Kalare Ianglo. Geofys. Publ. 0slo, 13, nr. 12, 19.14.

Tronso (1953). Publ. Norske Inst. Ko-m. Fys. nr. 34. Bencex, The auroral Observatory at Tromso. Obervations, 1951. 